\title{
Developing countries and international organizations: Introduction to the special issue
}

\author{
John W. McArthur ${ }^{1}$ - Eric Werker ${ }^{2}$ \\ Published online: 30 April 2016 \\ (C) The Author(s) 2016. This article is published with open access at Springerlink.com
}

\begin{abstract}
We describe four megatrends since the end of the Cold War that relate to developing countries: a greater share of the global economy; more accessible technologies, particularly in communication; breakthroughs in global cooperation in tackling basic human needs; and the evolution of a complex set of problems in spite of the progress. We then examine potential political economy channels that might hinder the ability of international organizations to adapt to the new realities. Introducing the articles to the special issue, we argue for four distinct variables that affect the behavior and character of international organizations: power, norms, preferences, and problems.
\end{abstract}

Keywords International organizations - Developing countries · Political economy · Power · Norms · Preferences · Global governance

The world of 2015, when the submissions for this special issue were received, was substantially different from the post-WWII world when the modern system of global governance through international organizations was established. In particular, the role and reach of developing countries and their citizens was in the midst of a major transformation. This special issue examines how, and how well, international organizations (IOs) are operating in this changed world. This journal, among others, has

Eric Werker

ewerker@sfu.ca

John W. McArthur

jmcarthur@brookings.edu

1 Brookings Institution, Global Economy and Development Program, 1775 Massachusetts Ave, NW, Washington, DC 20036, USA

2 Beedie School of Business, Simon Fraser University, 500 Granville Street, Vancouver, BC V6C 1W6, Canada 
published extensive research on how political economy issues have hindered the ability of IOs to efficiently and unbiasedly serve their members. ${ }^{1}$ For developing countries, who until recently have carried constrained economic or diplomatic weight, these political economy challenges have the potential to be even greater.

Before describing the most pertinent changes that characterize today's world as it relates to developing countries and IOs, it is worth describing the world of 1945-50 when the United Nations and Bretton Woods institutions were just taking off.

By 1950 there were only 60 member states in the United Nations - the newest of which was Indonesia, ${ }^{2}$ which had just won hard-fought independence from the Netherlands. But the British, French, and Portuguese empires still reached from southern to northern Africa, and all the way to Southeast Asia. The United States was twice as rich as France and five times as rich as Japan or Portugal. Argentina, Uruguay, and Venezuela had higher incomes than Western Europe. China's income per capita was a fifth that of Latin America (Maddison Project 2013).

Development aid was virtually nonexistent except for the creation and financing of the United Nations Relief and Rehabilitation Agency and the International Refugee Organization to stabilize Europe after WWII, followed by U.S. aid to Greece and Turkey and of course the Marshall Plan. Even the World Bank, which opened its doors in 1946 as the International Bank for Reconstruction and Development, was funding post-war reconstruction, primarily through guaranteeing private investment. Only through competition with the Soviet Union throughout the 1950s did the United States, and then later Western Europe, get into the business of foreign aid (Lancaster 2007).

Making an international phone call in 1950 would have necessitated multiple operators, and was extraordinarily inaccessible. A 3-min call from New York to London cost more than $\$ 50$ (in 2005 dollars) (Gordon 2016). That means that a 20 minute call would have eaten up the annual GDP per capita of an average Tanzanian - assuming they had the chance to be in New York or London in the first place. The high cost of communication placed major constraints on non-elites' ability to mobilize in order to demand and receive transparency from leaders and organizations.

That was the world in which the long-term scaffolding for global governance was put into place, even if the context kept evolving.

By the time the Cold War was coming to an end around 1990, global technology had advanced considerably and the era of colonialism had passed, with dozens of former colonies and protectorates gaining independence. Indeed, the United Nations grew to 159 members, with Namibia the most recent country to join following its independence from South Africa.

But the 1950 global distribution of economic development remained largely consistent, with the exception of a handful of East Asian countries that were rapidly

\footnotetext{
${ }^{1}$ Among the articles forthcoming in the Review of International Organizations at the time we wrote this introduction, examples include Manulak (2016) on the United Nations Environment Programme's secretariat, Peksen and Blanton (2016) on how the International Labor Organization (ILO) affects human rights, and Panke (2016) on the institutional design of IOs more broadly.

${ }^{2}$ United Nations website, "Member States," URL: http://www.un.org/en/members/growth.shtml, accessed Mar 182016.
} 
industrializing. Robert Barro's (1991) seminal paper on economic growth noted a general lack of convergence in per capita incomes. Many African countries like Ghana, Senegal, and Somalia were no better off income-wise than they had been at independence three decades before. Eastern European countries emerging from Communist rule were still around three quarters poorer than their western counterparts, the same ratio as at the beginning of their experiment with centrally-planned economies (Maddison Project 2013).

Meanwhile, the systems of foreign aid had become professionalized among multilateral organizations and most rich countries' own agencies. "Development" started to replace political alliances as aid's primary goal (Lancaster 2007), at least according to the rhetoric of western donors. Policy prescriptions were widely disseminated to developing countries based on the views of geographically concentrated intellectual elites. Long distance calling was certainly much cheaper, but for most developing countries it remained highly regulated by state-sanctioned monopolies. Cellular phones were starting to become available in a handful of rich countries, and the Internet was only used by technical specialists and dedicated hobbyists. The global communications revolution had yet to take hold.

All told, for IOs and developing countries, the post-WW II period from the late 1940s to the mid-1990s was characterized by an expanding but typically still paternalistic institutional reach. The World Bank had shifted from European reconstruction to financing development activities and urging policy frameworks in nearly all of the world's developing countries. The IMF had shifted from creating stability in the global fixed exchange rate regime to tackling debt problems in many developing countries. ${ }^{3}$ The United Nations began to send peacekeepers to civil wars - not just interstate conflicts - across the developing world. Its refugee arm had evolved from placing WWII refugees to intervening in conflicts in the developing world by providing assistance to internally-displaced persons (Barnett 2002).

\section{Megatrends}

The arc of history then began to inflect. A first transition occurred with the end of the Cold War, the beginning of the IT revolution, and a take-off in average living standards across much of the developing world. The seeds planted during this period would bear fruit by the 2010s, as the historic distinctions between "developed" and "developing" countries started to fade away. In the process, top-down approaches to governance like the so-called Washington consensus have been replaced by increasingly decentralized debates focused more on the pragmatics of solving specific global problems. IOs, particularly those tasked with solving the traditional problems of underdevelopment, are confronting the need to adapt.

A second geopolitical transition now seems to be underway too. No single factor explains what we dub the new "PUSH" era: a period in which international cooperation is increasingly framed around principles of problem-solving, universality, sustainability, and horizontal power structures. Instead it has been driven by at least four sets of underlying trends that have brought about this transition. These trends have changed

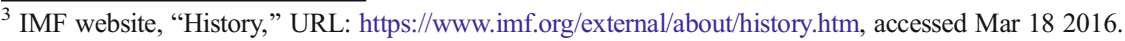


many underlying assumptions for cooperation as well as the modalities through which global problems are tackled. ${ }^{4}$

First, the composition of the world economy has shifted dramatically. As recently as 2000, the world's advanced economies of Western Europe, North America, Japan, and Australasia remained the core drivers of overall global economic progress. According to the World Bank's income classification criteria, the 33 countries classified as highincome as of 2000 had only $15 \%$ of the world's population but accounted for $78 \%$ of the world's economic output and $70 \%$ of its growth (World Bank 2016). These countries had considerable geopolitical influence by virtue of the scale of their economic influence.

By 2013, the same countries were still responsible for a majority of the world's economic output, although on current trend that share will dip below half within the coming decade. More tellingly, the advanced economies are now responsible for just two fifths of the world's economic growth. Thus countries that have historically been categorized as "developing" are now driving a sizable majority of the world economy's underlying changes.

Living standards have improved along with the growth in income. As of 2000, approximately $28 \%$ of the world's population lived under the "dollar a day" standard of extreme poverty. ${ }^{5}$ By 2015 , the corresponding share was estimated to have dipped below $10 \%$ (Cruz et al. 2015). Linked to the overall progress in living standards, the "global middle class," measured by those with incomes of at least \$US 10-100 per day, is estimated to have grown from approximately 1.5 billion in 2000 to nearly 3 billion today, en route to 5 billion by 2030 (Kharas 2010).

The economic underpinnings of global influence have realigned such that the traditionally dichotomous terminology of "developed" and "developing" countries is increasingly irrelevant. China, for instance, is categorized by the World Bank as a developing economy, even though it is now the world's largest economy in purchasing power parity terms, the largest emitter of greenhouse gases, and the largest financier of the world's newest major multilateral institutions, the Asian Infrastructure Investment Bank and the New Development Bank (or "BRICS bank").

Most nation states are facing an increasingly common set of underlying policy challenges, even if those challenges might manifest in different ways in different places. Thus it was seminal, in July 2015, when the major UN international conference on Financing for Development in Addis Ababa underscored domestic government revenues, not foreign aid, as the most crucial ingredient of global development finance.

A second dramatic shift has taken shape through rapid advances in the ability for people from all parts of the globe to interact and share ideas, enabled by advances in information and communications technologies and declining long terms costs for international travel. A variety of indicators illustrate the trend. The telephone call mentioned earlier between London and New York can now be conducted for free via

\footnotetext{
${ }^{4}$ See Biggs et al. (2015) for a more in depth review of relevant megatrends. Jenks and Kharas (2016) also explore how changes in the global economy affect the need for changes in multilateral development institutions.

${ }^{5}$ This is based on the Ferreira et al. (2015) estimate of a 1999 poverty headcount rate of $29 \%$ of the global population living below $\$ 1.90$ in 2011 purchasing power parity terms, followed by a slightly faster than 1 percentage point annual rate of decline over the subsequent twelve years, down to approximately $14 \%$ reported for 2011.
} 
the internet. Cross-border bandwidth use is growing at more than $50 \%$ per year (McKinsey Global Institute 2016). In 2000 there were 12 mobile cellular subscriptions and 7 Internet users per 100 people around the world. By 2014 the corresponding figures were 96 and 41, respectively (World Bank 2016). Even in low-income countries, the mobile cellular subscription ratio is 57 per 100 people, although internet still remains very low at 6 per 100 (ibid).

The spread of economic growth and communications technology has enhanced the diffusion of knowledge and ideas. Scientific insights and political opinions are able to travel more quickly. In some countries this has supported advances in democracy, although long-term causal pathways remain a subject of debate. The percentage of the world living in democratic political systems has remained stable near $50 \%$ for the past two decades (Roser 2015). ${ }^{6}$

A third trend has taken shape in the form of improved international policy cooperation in tackling basic human needs. Some of this has been prompted by the emergence of policy orthodoxies that prioritize direct investments in human capital, primarily through health and education, alongside more market-focused institutional conditions. The Millennium Development Goals were launched in the early 2000s as an attempt to promote universal access to the benefits of globalization by 2015. Over time the goals became a common reference point for development-focused international cooperation and the stated goals of many IOs.

Many of the new cooperation norms have been forged through advances in global health. By one estimate more than 15 million additional people are alive today than would have been under business-as-usual trajectories as of the early 2000s (McArthur 2014, 2015). Much of this has been supported by the launch of new outcome-oriented IOs like the Global Alliance for Vaccines and Immunizations (the GAVI Alliance) and the Global Fund to Fight AIDS, TB and Malaria. These problem-focused institutions were launched with innovative governance structures aiming to bridge perspectives and resources across donor governments, recipient governments, civil society, scientific communities, and the private sector. Clear outcome-oriented mandates also enabled a norm of learning-by-doing. When the Global Fund's internal audit function identified patterns of misspending, the ensuing political tensions prompted a rapid organizationwide overhaul of procedures.

As goal-oriented cooperation norms took hold across a wide range of previously disparate international constituencies (Davis et al. 2012), expectations took shape around the need for an updated generation of policy goals that could speak to an updated global context. This in turn led to the Sustainable Development Goals, established in September 2015 by all (now) 193 UN member states as a series of economic, social, and environmental targets for 2030, which all countries agreed to pursue on a voluntary basis.

The fourth set of trends reflects the frontier challenges for international cooperation. Some of these are the residual issues or marginalized populations that have not been addressed by recent global gains. For example, many whom Paul Collier (2008) described as the "bottom billion" remain stuck in a handful of self-reinforcing traps. Fragile and conflict-affected states have also experienced far less progress on benchmarks like the MDGs or on corruption ratings than similarly poor but stable countries.

\footnotetext{
${ }^{6}$ Summing across the Polity IV categories of full democracy and democracy.
} 
Meanwhile, the most complex emergent challenges are those linked to global public goods (and "bads") where each new unit of economic progress is generating a proportionate increment of global societal challenge. This is most pronounced in the realm of natural resource management, ranging from biodiversity to oceans to climate change.

\section{Can international organizations respond to the changing world?}

Governmental institutions can be slow to adapt as they do not always possess the incentives, processes, and organizational structures to solve the right problems (Wilson 1989; Haas 1990). There are a variety of mechanisms through which political economy channels influence the ability of IOs to change their activities and outlook to respond to changing global conditions.

One mechanism is through national interests. IOs are set up with governance structures that distribute power among member states in particular ways-whether through explicit or de facto representation on an executive board or secretariat, or through vulnerability to back-channel lobbying (e.g., Kaja and Werker 2010; Stone 2013; Novosad and Werker 2014). These power structures can be baked into the original institutional design, like the veto membership in the U.N. Security Council (Koremenos et al. 2001). This means that once an IO is up and running, countries with better access to control face incentives to look after their national interest, even when the IO itself might be better served taking a different path.

A second is through the IO's leadership and professional cadre. IOs exhibit some degree of autonomy from their members, often by design (Nielson and Tierney 2003; Barnett and Finnemore 2004). As "agents" to the IO member states' "principals", the leaders of an organization can reinterpret their mandate and rules (Hawkins and Jacoby 2006). This would bring in the judgment of professionals and experts to complement the realpolitik of member state representatives. IO professionals can also be invested in particular norms, and use their platform as a means to spread those norms (Finnemore 1993). Even when these norms are static, their moment in world affairs might be on the rise (Florini 1996), thereby raising the ability of those IOs that adhere to such a world view to take on a more prominent role.

A third is through grassroots beliefs and norm "entrepreneurs". Transnational advocacy networks can influence IO behavior through the introduction or propagation of new norms (Park 2005). Political or norm entrepreneurs utilize these networks to advance their campaigns through the provision of information, framing, and leverage (Keck and Sikkink 1998). In so doing, they can change the incentives faced by both IO professionals and the member states that oversee them. As the political power of different interest groups rise, they may have more success in championing their issues through transnational networks or domestic politics, which can reverberate onto changed IO behavior.

A fourth is through attrition and the formation of new organizations. As in any industry, there is creative destruction in the field of IOs that determines which IOs are present and what their market share is (in terms of member state attention, programming, influence, and so forth). Unlike with usual product markets, however, IOs live and die by their funding and not their end users' demand. Thus, many IOs endure as 
"zombies" with just an organizational shell but no effective activity (Gray 2012). According to the Union of International Organizations, there were some 68,000 IOs in 2015 (including many non-governmental organizations), 30,000 of which were dormant. Some 1200 new IOs are added each year. ${ }^{7}$ That allows for a combination of creation and attrition to respond to the changing mix of issues as the world undergoes significant transition.

\section{Purpose of the special issue}

An open call for papers for the special issue on developing countries and IOs was issued to coincide with the Political Economy of International Organizations 2015 conference in Berlin. The focus was not on a narrow theoretical question or a specific area of the academic literature. Rather, the goal was to enhance our understanding of how international institutions were accommodating, responding to, and evolving based on pressures from a part of the world that was playing an increasingly important role.

The call requested submissions in three areas in which the greater role of developing countries in the global economy would interface with the political economy of IOs. First, rising-power developing countries such as Brazil, China, and India seek to play a larger role in global IOs; how this effort pans out may ultimately determine the trajectory of these organizations during the coming decades. Second, there are regional IOs with membership restricted to certain developing countries, and these IOs may present characteristics that call into question the conventional narrative generated from global or rich-country regional IOs. Third, developing countries are often the location of IO activity such as program implementation and execution, each of which can be affected by political economic forces.

The journal received a large number of submissions examining different aspects of the relationship between IOs and developing countries, focusing on a diverse set of international institutions and developing-country stakeholders, while deploying a handful of different methodologies. The submissions highlighted the reach of IOs and the breadth of their interface with developing countries, as well as the diversity of global governance solutions to problems that originate in, or affect, the developing world. Ultimately only a few of the submissions could be published.

The four articles in this special issue cover all three areas of the call for papers as well as three of the four channels through which political economic forces might affect IOs' ability to adapt to the megatrends identified in section 2. Below we summarize each of the articles, revisit the theoretical discussion, and offer a synopsis of how the capabilities of our international institutions to respond to the issues of our day might be better understood.

\section{Articles in the special issue}

In "Imperfect Adaptation: How the WTO and the IMF Adjust to Shifting Power Distributions among their Members," Zangl et al. (2016) tackle the question of how

\footnotetext{
${ }^{7}$ Union of International Associations yearbook, website: http://www.uia.org/yearbook, accessed Mar 212016.
} 
rising powers are accommodated within existing IOs. They observe that when new powers like Brazil, China, and India emerge and established powers like the United States, the United Kingdom, and France decline, IOs only sometimes adapt to the new power dynamic by redistributing institutional privileges. The authors posit that traditional power transition theories imperfectly explain if and how the international order adapts to changing power dynamics, proposing institutionalist power shift theory (IPST) as an alternative.

IPST proposes that whether or not emerging powers succeed or fail to bring about institutional adaptation depends on their ability to undermine the existing international order, and whether threats to this effect are credible. IPST is fleshed out with two examples. In the first, Brazil and India successfully renegotiated the composition of the WTO core negotiating group, the "Quad," a consortium of nations that dominate WTO decision-making then made up of the United States, the European Union, Japan, and Canada. Brazil and India were able to displace Japan and Canada from the group through a combination of sabotage, threats, and promises - thus reflecting the emerging nations' rising power position. In the second example, China successfully lobbied to change IMF surveillance practices, which had previously focused solely on exchange rate issues. The new surveillance policy targeted both developing and developed nations as potential sources of global financial instability, thus becoming more evenhanded.

In each of these examples, emerging powers were capable of bringing about changes to international institutional order by making credible threats to undermine the existing order, setting the context for successful negotiation and adaptation. Zangl et al. utilize IPST to make predictions about the likelihood and content of U.N. Security Council, nuclear non-proliferation treaty, and IMF/World Bank leadership reform. The paper falls squarely in the first category of channels described in section 2: how political economy forces affect the ability of national interests to be accommodated in IOs as the international distribution of power changes. With IPST, the authors put forward a compelling and parsimonious framework to describe that process.

Felix Anderl (2016) questions the conventional wisdom of how norms are spread to developing countries in "The myth of the local: How international organizations localize norms rhetorically." Anderl uses ethnographic methods in an examination of a regional IO that champions south-south development cooperation, the Center for Integrated Rural Development for the Asia Pacific (CIRDAP). The study reveals that the IO does not "localize" global norms (Acharya 2004): framing its practices with global norms while deviating from them by incorporating local norms. Rather, CIRDAP publicly denounced global development norms as "Western" and purported to apply local development frameworks. But the normative frameworks employed to achieve poverty alleviation borrow heavily from global frameworks such as the Millennium Development Goals, while the success or failure of these efforts are typically measured against global benchmarks such as the Human Development Index. Heavy reliance on these instruments and benchmarks runs in stark contrast to the myriad of speech acts, both internal and external, which assert the primacy of the local.

Anderl thus argues that "the local" is a myth, a rhetorical concept used to legitimize IO initiatives at the local level. Changes in the global discourse that now privilege local solutions, in part due to the rise of developing countries and their perceived successes, force a localization of practices that Anderl finds lack substantial content. This 
"rhetorical localization" does have some potential benefits for developing countries in that it opens up channels through which local norms can feed back into global discourse. But it also creates a danger in that the veneer of local ownership might be easily cracked or, if it is not, that developing countries remain subject to an agenda driven by developed-country political forces.

Anderl's paper examines one aspect within the second channel described in section 2: that an IO's professional staff can influence how an IO adapts to a changing set of circumstances on the ground, through the choice of instruments and methodology for executing on the IO's mission. By borrowing from global practices, the staff unconsciously utilizes global norms at the cost of local resourcefulness and flexibility, hence diminishing the IO's potentially unique contributions.

In "Citizen Preferences and Public Goods: Comparing Preferences for Foreign Aid and Government Programs in Uganda," Milner et al. (2016) elevate the view of developing-country citizens in evaluating the legacy of IO interactions with the developing world. Critics of foreign aid, not to mention of structural adjustment policies of the IMF and World Bank, have painted a picture of aid and IOs perpetuating corruption, conflict, and poverty (e.g., Easterly 2006).

Milner, Nielson, and Findley employ randomized behavioral experimental techniques to unpack competing theories of the impact of foreign aid in light of actual citizens' perceptions of aid in Uganda. Whereas the "aid capture" theory gives greater influence to recipient governments, who are depicted as diverting fungible foreign aid to their own use at the expense of citizen well-being, the "donor control" theory places greater influence on aid donors. In the latter model, donors are interested in using aid not just for geo-strategic purposes, but also for development and reform; donors target aid in ways that make it less fungible and vulnerable to government capture, thus allowing it to reach the government's citizens. Each theory makes a distinct prediction about citizens' attitudes toward the impact of foreign aid in recipient countries.

In the study, 3600 Ugandan citizens were asked a series of demographic and attitudinal survey questions and then presented with an actual description of a pipeline aid project that was either depicted as funded by the Ugandan government or by foreign aid. The citizens were then asked to express support for the project by signing a petition or sending an SMS text message. Citizens were significantly more likely to express support, sign the petition, and send the SMS text message for projects funded by foreign aid. Those Ugandans who perceive the government as corrupt or do not support the ruling party were even more trusting of foreign aid over government spending. The results, and the behavior they depict, are consistent with the "donor control" theory, which sees donors as capable of directing aid to meet the needs of citizens. Interestingly, citizens did not display particular preferences across different IOs but viewed them all favorably - more favorably than their own government.

The channel of influence from section 2 that Milner, Nielson, and Findley investigate is the third one, in which changing grassroots beliefs and power of different constituencies should get reflected in changed IO behavior. One powerful result from the surveys was the profoundly high degree of political knowledge among those surveyed, consistent with the information revolution and success in basic education. As the typical citizen in a developing country gains more knowledge in general, and about her government's actions in particular, she will influence the potential action set of her leaders. Milner, Nielson, and Findley's finding of Ugandan citizens' positive 
views towards IOs may actually indicate that IOs need not change as much as one might imagine, in cases where citizens may hold preferences closer to IOs' than to their own government's.

In the final article, "Resisting Democracy Assistance: Who Seeks and Receives Technical Election Assistance," Inken von Borzyskowski (2016) explores the phenomenon of low levels of election assistance despite the weakness of democratic institutions in many countries. Interestingly, while election observation has emerged as a new norm, technical election assistance is far rarer. While countries made use of election observation two thirds of the time, the use of technical election assistance is far lower, at only one quarter in the early 2000s. This gap between observation and technical support persists today, with about three quarters of elections having monitors but only half receiving technical assistance in 2012. The United Nations has also at times resisted providing technical election assistance, doing so only three fifths of the times it was requested during 1990-2003. In contrast, if countries invited observers, some observer group heeded their call in virtually all cases.

Using data on national elections of 130 countries, von Borzyskowski examines the determinants of country requests for technical assistance as well as the United Nations' actual provision of technical election assistance. She finds that countries that are more autocratic (with a high cost politically of being undermined through more legitimate elections) and that already have stronger electoral institutions are less likely to request assistance. On the provider side, the United Nations tends to decline technical election assistance to incumbents that appear to lack the will to reform, as proxied by short lead times before the election. This is consistent with the IO maximizing the return on its investment in the program delivery. These findings help explain the lower level of election assistance activity compared to election observation.

This article does not speak directly to the political economy channels through which IOs might have trouble adapting to the significant global changes that we described earlier. Rather, it explores one political economic dynamic of IOs within the fourth megatrend: that of "residual issues" not yet addressed by the global gains. Many countries remain only weakly democratic in spite of decades of IO and bilateral aid agency interventions to improve the functionings of their democracy. Von Borzyskowski highlights the challenges to ameliorate this situation when the potential recipients are led by individuals concerned with protecting their privileges, and IOs are trying to invest their resources effectively.

Finally, it is worth mentioning a paper that is not here. To round out the mechanisms through which IOs could collectively respond to the megatrends described earlier, we would ideally have been able to publish a paper describing some aspect of the birth, life-cycle, and death ${ }^{8}$ of (particular) IOs following changes in the issue set demanded by the situation in member countries across the globe.

\section{Towards a conceptualization of developing countries' influence on IOs}

Each of the articles interrogates a key variable that should drive the positioning, behavior, and substance of international institutions. Zangl et al. focus on the variable

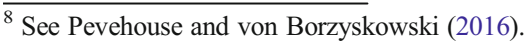


of power, which has gone up, especially for large middle-income developing countries, and determines the potential influence of members. Anderl concentrates on the variable of norms, which in theory will differ between and among developed countries and developing countries, and affects the approach, conversation, and mandate inside IOs. Milner, Nielson, and Findley scrutinize the variable of citizen preferences, which take into account lived experience, and ought to ultimately form the bedrock of policy formation. Von Borzyskowski analyzes the variable of problems, which still persist and evolve in todays' developing countries, despite two decades of progress, and will continue to influence the issue set faced by IOs.

Figure 1 depicts these four variables in a simple framework. Power, norms, preferences, and to some extent the set of problems, intermediated by and between national governments, should together characterize the interests that are embedded in IOs or reflected in their behavior. To be sure, the interests that emerge through norms or citizen preferences will be more subtle and occur through different channels than through power. Norms, preferences, and problems, in particular those common problems whose solutions necessitate the production of global public goods, should drive the substantive focus of IOs. Each resultant IO can then conduct a suite of activities, broadly defined, which generate impact and change outcomes. Of course, some IOs are far more effective at generating impact than others (Levy et al. 1993). Resources, for instance, play a role here but those will be driven by similar variables. We leave IOs as "black boxes" in the figure but hardly think of them as such. A rich literature unpacks them in various ways, with this journal contributing to that body of knowledge.

The simple figure can be helpful for thinking about IO behavior through two complementary devices. First, one can utilize it to brainstorm how changes in the independent variables (power, norms, preferences, and problems) might affect IOs and their work, and eventually their impact. In this essay we approach this question from a $30,000 \mathrm{ft}$ view. One could also use this framework to tackle a single IO's adaptation to a particular change in its environment from a more ground-level perspective. As the variables of power, norms, preferences, and problems change according to the megatrends we identify, then so too should there be change in the structure, activities, and behavior of the IOs that interface with today's developing world.

Second, one can use this framework to examine political economy forces, which intersect with each of these variables and, in so doing, leave some doubt about how smoothly any predictions of changes in IOs might be realized. As described earlier, IO structure, staff, and transnational norms are some of the ways in which political interests scuttle or enable transformation.

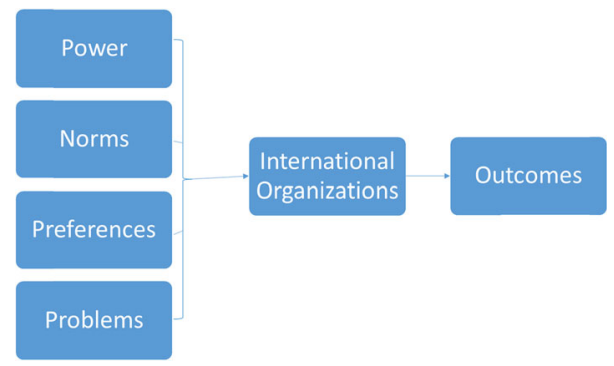

Fig. 1 Formation and Change in IOs 


\section{Conclusion}

The literature on IOs and developing countries is varied and rich, but for the most part publishes without referencing the extraordinary shifts occurring in the world and the central role of IOs in potentially responding and adapting to them. The goal of this introduction is to identify a research agenda for this collective work, and to ground it in a handful of exemplary articles that collectively offer a narrative of how developing countries are changing the landscape of global governance.

Extraordinary geopolitical changes have already started to take hold. Developing countries and their citizens have unprecedented, if incomplete, potential influence over global governance. It would not be far-fetched to forecast a wholesale reconstruction of the international order that better reflects the new distribution of power, norms, and preferences and responds more efficiently to the world's current problems.

The papers gathered here, however, present a far more restrained picture.

On the question of rising developing country power being realized in IOs, Zangl et al. argue for a more incremental, yet occasionally disruptive transition in which institutions are slow to change, and only the threat of exit by a rising power generates a successful adaptation. Since the activation energy required to signal exit is not insignificant, this would lead us to expect that the status quo will be sticky more often than not.

As for whether norms rooted in developing countries permeate IO agendas and messaging, Anderl describes omnipresent global norms permeating even entirely southern activities. The reach of the global conversation may indicate a more uniform (if not universal) set of values and priorities that, left unchallenged, do not predict dramatic imminent change in IO-influenced outcomes, even when developing countries are better represented in senior IO leadership positions.

When it comes to preferences of developing country citizens being integrated into IO activities, Milner, Nielson, and Findley demonstrate that these citizens can actually have a high degree of trust and respect for IOs - even more than for their national governments. This points to the continued role of IOs influencing developing-country government leaders rather than the other way around.

Finally, regarding the practical issues of solving developing countries' own problems, in section 1 we briefly outlined some of the world's complex sticky problems that persist in spite of all its progress. As von Borzyskowski elucidates in her study of election assistance, the problem of political representation in developing countries and an IO's attempt to solve it both remain mired in political economy challenges. Those countries where election assistance would be most beneficial are often precisely those where it does not occur. This finding should give pause to anyone who might simply outsource to IOs the task of solving the world's biggest collective problems.

Among such problems, climate change looms large. However, the 2015 COP-21 climate conference in Paris provided seeds of hope for new forms of multilateral cooperation. It presented the first occasion on which all countries agreed to pursue national strategies that would reduce their greenhouse gas emissions compared to a business-as-usual trajectory.

Existing national strategies are not yet adequate to achieve the desired ceiling of 1.5-2.0 degrees Celsius average global temperature increase, but the norm of launching peer-reviewed national plans toward the achievement of a common goal represents a 
key juncture in the historical arc of global governance. Each sovereign state is understood to have equal legitimacy in setting their own economic and environmental course, but each is also subject to the norms and pressures, both domestic and international, of identifying how they will ultimately be viewed as contributing to the solution rather than the problem.

These and other emerging forms of international cooperation help to frame a new research agenda for the study of IOs. How, for example, do the preferences of individuals and the capabilities of private organizations and global communities get represented in global institutions? When do specific problems generate autonomous IOs that can work efficiently to solve them? And how might new subject-specific forms of international cooperation on emergent issues, such as climate change or pandemic disease control, support the launch of new forms of international cooperation on residual challenges like fragile states?

Over the coming years, researchers will need to pay close attention to the shifting patterns among IO norms and practices, and to the broader ability of IOs and global governance institutions to keep step with the world and its challenges. The papers in this volume provide important contributions in helping to understand some key attributes of the changes underway.

Acknowledgments We are grateful to Felix Anderl, Inken von Borzyskowski, Axel Dreher, Homi Kharas, Helen Milner, and Daniel Nielson for helpful discussions and feedback. Our views on the megatrends were formed through extensive collaboration with Margaret Biggs, Kate Higgins, David Moloney, and Julia Sanchez. Meghan Parker and Krista Rasmussen provided excellent research assistance. The usual disclaimer applies.

Open Access This article is distributed under the terms of the Creative Commons Attribution 4.0 International License (http://creativecommons.org/licenses/by/4.0/), which permits unrestricted use, distribution, and reproduction in any medium, provided you give appropriate credit to the original author(s) and the source, provide a link to the Creative Commons license, and indicate if changes were made.

\section{References}

Acharya, A. (2004). How ideas spread: Whose norms matter? Norm localization and institutional change in Asian regionalism. International Organization, 58(02), 239-275.

Anderl, F. (2016). The myth of the local: How international organizations localize norms rhetorically. Review of International Organizations, 11(2).

Barnett, L. (2002). Global governance and the evolution of the international refugee regime. International Journal of Refugee Law, 14.2 and 3, 238-262.

Barnett, M., \& Finnemore, M. (2004). Rules for the world: International organizations in global politics. Ithaca, New York: Cornell University Press.

Barro, R. J. (1991). Economic growth in a cross section of countries. The Quarterly Journal of Economics, $106(2), 407-443$.

Biggs, M., McArthur, J. W., Higgins, K., Moloney, D., Sanchez, J., \& Werker, E. (2015). Towards 2030: building Canada's engagement with global sustainable development. In Centre for International Policy Studies. Ottawa, ON: Working paper.

von Borzyskowski, I. (2016). Resisting democracy assistance: Who seeks and receives technical election assistance? Review of International Organizations, 11(2).

Collier, P. (2008). The bottom billion: Why the poorest countries are failing and what can be done about it. USA: Oxford University Press.

Cruz, M., Foster, J., Quillin, B., and Schellekens, P. (2015). Ending extreme poverty and sharing prosperity: progress and policies. Washington, DC: World Bank Policy Research Note. 
Davis, K. E., Kingsbury, B., \& Merry, S. E. (2012). Indicators as a technology of global governance. Law and Society Review, 46(1), 71-104.

Easterly, W. (2006). The White Man's Burden: Why the West's Efforts to Aid the Rest Have Done So Much Ill and So Little Good. Westminster, London: Penguin.

Ferreira, F. H., Chen, S., Dikhanov, Y., Hamadeh, N., Jolliffe, D., Narayan, A., Prydz, E.B., Revenga, A., Sangraula, P., Serajuddin, U., \& Yoshida, N. (2015). A Global Count of the Extreme Poor in 2012: Data Issues, Methodology and Initial Results. Washington, DC: World Bank Policy Research Working Paper, (7432).

Finnemore, M. (1993). International organizations as teachers of norms: The United Nations educational, scientific, and cultural organization and science policy. International Organization, 47(04), 565-597.

Florini, A. (1996). The evolution of international norms. International Studies Quarterly, 40(3), 363-389.

Gordon, R. (2016). The Rise and Fall of American Growth: The U.S. Standard of Living Since the Civil War. Princeton: Princeton University Press.

Gray, J. (2012). Life, death, or zombies? The endurance of inefficient regional economic organizations. Conference paper from Political Economy of International Organizations conference. Princeton, NJ: Princeton University.

Haas, E. B. (1990). When knowledge is power: Three models of change in international organizations (Vol. 22). Oakland, California: Univ of California Press.

Hawkins, D. G., \& Jacoby, W. (2006). How agents matter. Delegation and Agency in International Organizations. Cambridge, UK: Cambridge University Press.

Jenks, B., \& Kharas, H. (2016). Toward a new multilateralism. New York, NY: Mimeo.

Kaja, A., \& Werker, E. (2010). Corporate governance at the World Bank and the dilemma of global governance. The World Bank Economic Review, 24(2), 171-198.

Kharas, H. (2010). The emerging middle class in developing countries. OECD Development Center, Working Paper 285. January.

Lancaster, C. (2007). Foreign aid. Chicago: University of Chicago Press.

Levy, M. A., Keohane, R. O., \& Haas, P. M. (1993). Improving the effectiveness of international environmental institutions. Institutions for the earth: Sources of effective international environmental protection, 397-426. Cambridge, MA: The MIT Press.

Keck, M. E., \& Sikkink, K. (1998). Activists beyond borders: Advocacy networks in international politics (Vol. 6). Ithaca: Cornell University Press.

Koremenos, B., Lipson, C., \& Snidal, D. (2001). The rational design of international institutions. International Organization, 55(04), 761-799.

Maddison Project database. (2013). URL: http://www.ggdc.net/maddison/maddison-project/home.htm, 2013 version, accessed Mar 182016.

Manulak, M.W. (2016). Leading by design: Informal influence and international secretariats, Review of International Organizations, forthcoming.

McArthur, J. W. (2014). Seven million lives saved: Under-5 mortality since the launch of the Millennium Development Goals. Brookings Global Economy and Development Working Paper 71. September.

McArthur, J. W. (2015). 15 million success stories under the millennium development goals. Brookings Up Front. September 24. http://www.brookings.edu/blogs/up-front/posts/2015/09/24-million-success-storiesmillennium-development-goals-mcarthur

McKinsey Global Institute (2016). Digital Globalization: The New Era of Global Flows. New York, NY: McKinsey and Company.

Milner, H. V., Nielson, D. L., \& Findley, M. G. (2016). Citizen preferences and public goods: Comparing preferences for foreign aid and government programs in Uganda. The Review of International Organizations. doi:10.1007/s11558-016-9243-2.

Nielson, D. L., \& Tierney, M. J. (2003). Delegation to international organizations: Agency theory and World Bank environmental reform. International Organization, 57(02), 241-276.

Novosad, P., \& Werker, E. (2014). Who runs the international system? Power and the staffing of the United Nations secretariat. Harvard Business School BGIE Unit Working Paper, (15-018).

Panke, D. (2016). Speech is silver, silence is golden? Examining state activity in international negotiations, Review of International Organizations, forthcoming.

Park, S. (2005). Norm diffusion within international organizations: A case study of the World Bank. Journal of International Relations and Development, 8(2), 111-141.

Peksen, D. and R. G. Blanton. (2016). The impact of ILO conventions on worker rights: Are empty promises worse than no promises? Review of International Organizations, forthcoming. 
Pevehouse, J., and von Borzyskowski, I. (2016). International Organizations in World Politics. In The Oxford Handbook of International Organizations, edited by Cogan, J.K., Hurd, I., and Johnstone, I. chapter 1, forthcoming.

Roser, M. (2015). Democratisation. OurWorldInData.org. URL: http://ourworldindata.org/data/politicalregimes/democratisation/ accessed Mar 232016.

Stone, R. W. (2013). Informal governance in international organizations: Introduction to the special issue. Review of International Organizations, 8(2), 121-136.

Wilson, J. Q. (1989). Bureaucracy: What government agencies do and why they do it. New York, NY: Basic Books.

World Bank. (2016). World Development Indicators online. Accessed at http://data.worldbank.org/datacatalog/world-development-indicators.

Zangl, B., Heußner, F., Kruck, A., \& Lanzendörfer, X. (2016). Imperfect adaptation: How the WTO and the IMF adjust to shifting power distributions among their members. The Review of International Organizations. doi:10.1007/s11558-016-9246-Z. 